\title{
Peripheral Osteoma of The Angle of Mandible
}

Sailaxmi Gopanaboina², Pavan Kumar², Yashwanth Yadav 3 , Madhusudhana Rao ${ }^{4}$

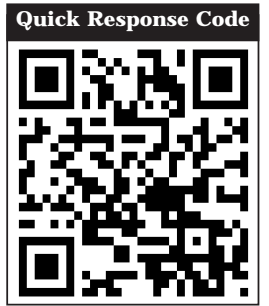

doi: $10.5866 / 2016.8 .10259$

${ }^{1}$ Post Graduate

${ }^{2}$ Professor \& HOD

${ }^{3}$ Assistant Professor

${ }^{4}$ Reader

Department of Oral \& Maxillofacial Surgery,

Kamineni Institute of Dental Sciences,

Narketpally- 508254.

\section{Article Info:}

Received: October 13, 2016

Review Completed: November 12, 2016

Accepted: December 11, 2016

Available Online: December, 2016 (www.nacd.in)

(c) NAD, 2016 - All rights reserved

\section{Email for correspondence:}

munnyg29@gmail.com

\begin{abstract}
:
Osteomas are benign osteogenic lesions with very slow and continuous growth seen in the craniofacial region, most commonly affecting temporal bones, sinuses, maxilla or mandible. They are characterized by the proliferation of compact or cancellous bone. It is usually asymptomatic and it is often detected incidentally on routine radiographic examination or until it causes facial asymmetry or dysfunction. The peripheral osteoma of the jaw is uncommon. We present a case of solitary peripheral osteoma of the angle of the mandible in a 26-yearold female with clinical, radiologic, and histopathol ogic findings.
\end{abstract}

$\overline{\text { Key words: Osteomas, Peripheral osteoma, Angle of mandible }}$

\section{INTRODUCTION}

Osteomas are relatively rare benign osteogenic neoplasms characterized by the proliferation of compact and/or cancellous bone. Osteomas can develop as peripheral (periosteal) masses attached to the cortical plates or as central lesions arising from endosteal bone surfaces whereas the extraosseous form develops in muscular tissue structures. ${ }^{1,2}$ Histologically, osteomas may be of two types: (a) compact and (b) cancellous. Compact osteomas consist of dense, compact bone with a few marrow spaces, while cancellous osteoma is characterized by bony trabeculae and a fibrofatty marrow enclosing osteoblasts which resembles mature bone. ${ }^{3}$

Peripheral osteoma is an uncommon lesion, mostly occurring in young adults, which affects equally men and women. It mainly affects the frontal bone, mandible, and paranasal sinuses. Mandibular cases occur in the angle or condyle, followed by the 
molar area of the mandibular body and ascending ramus. ${ }^{4}$ When osteoma is diagnosed one should not discard the possibility of Gardner's syndrome. Multiple osteomas of the facial bones are an important early marker for Gardner's syndrome. In the present case report, we present a case of a solitary peripheral osteoma arising at the left angle of the mandible.

\section{CASE REPORT}

A 26 year old female patient reported to the department of oral and maxillofacial surgery with a chief complaint of swelling in the left lower jaw region. The patient gave the history that the swelling was first noticed about one year back which was insidious in onset, and gradually increased to the present size. The patient did not give any history of trauma or infection in that region. On clinical examination, a solitary swelling approximately 1.5 $\mathrm{cm} \times 1.5 \mathrm{~cm}$ in size was seen at the left angle region of the mandible (Figure 1). On palpation, the swelling was bony hard in consistency, non-tender, non-pulsatile and non-compressible with no local rise in temperature. Intra oral examination did not reveal any abnormality. The swelling was fixed to the underlying bone.

An orthopantomograph was advised which showed well defined, irregularly oval radiopaque mass surface attached to the inferior border of the mandible in the left angle region (Figure 2). The computed tomography (CT) scan and 3D reconstruction showed a well circumscribed, pedunculated homogeneous bony mass attached to buccal cortex at the left angle of the mandible (Figure 3). Based on the clinical and radiographic features, a provisional diagnosis of a peripheral osteoma was made. The lesion was treated by surgical excision using an extra oral submandibular approach under general anaesthesia. Submandibular incision was marked and layer wise dissection was carried out and lesion was exposed. Excision of the lesion was done using 703 bur, chisel and mallet (Figure 4). Yellowish solid mass of about $1.5 \mathrm{~cm}$ in diameter was visualized (Figure 5). The surgical specimen was submitted for histopathological examination. Layerwise closure was done followed by pressure dressing. $\mathrm{H}$ istopathol ogical examination of thelesion revealed densely arranged bony trabeculae with scattered osteocytes in the lacunae, interspersed within the dense bone along with the presence of marrow elements, which confirmed the diagnosis of compact osteoma.

\section{DISCUSSION}

Osteoma is a benign slow growing osteogenic lesion characterised by proliferation of compact or cancellous bone. As sol itary peripheral osteoma may be clinically silent for years without symptoms, it is usually diagnosed when it becomes enlarged or is incidentally discovered by radiological examination such as panoramic radiography or CT. In somecases the size of the tumor may cause facial deformity or functional impairment. In our case, the lesion is single and silent and initially without any symptoms; however, it is gradually enlarged over a period of one year to reach a size of $1.5 \times 1.5 \mathrm{~cm}$.

The pathogenesis of peripheral osteomas is still controversial. Some consider it a true neoplasm, and others classify it as a reactive condition triggered by trauma, because peripheral osteomas generally are located on the lower border or buccal aspect of the mandible, which are often trauma prone areas. ${ }^{5}$ Combination of trauma and muscle traction may play a role in its development; that is, the trauma may cause subperiosteal bleeding or oedema that would locally elevate the periosteum. ${ }^{6}$ This might initiate an osteogenic reaction that could be perpetuated by continuous muscle traction. The present case had no history of trauma. Clinically, peripheral osteoma appears as a unilateral, sessile or pedunculated, well circumscribed, mushroom like mass larger from 10 to $40 \mathrm{~mm}$ in diameter. There is no predilection for age, sex. Although an osteoma can arise at any age, it seems to be more common among young adults. ${ }^{6}$ In the present case, the computed tomography (CT) scan showed a wellcircumscribed, radiopaque mass with a broad base attached to the left angle of the mandible. 


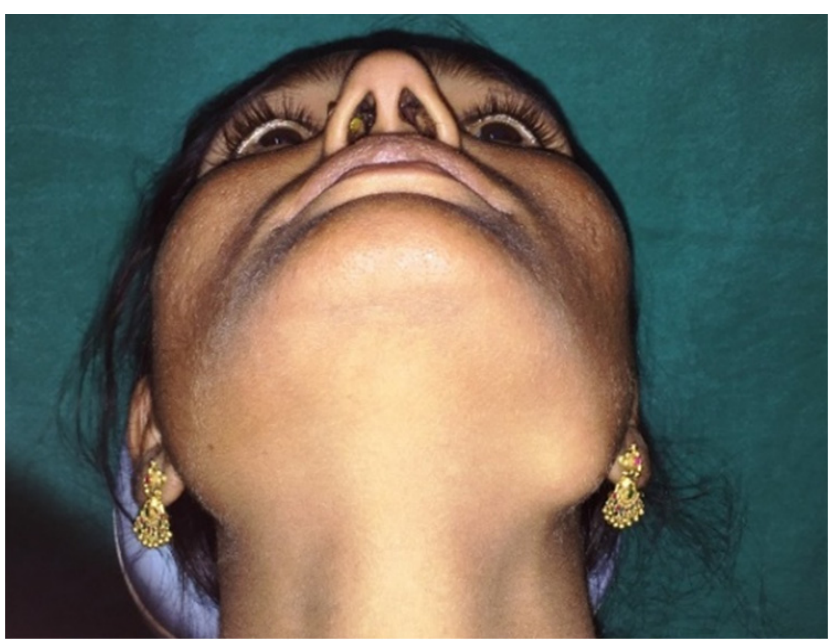

Figure 1: A 26 year old female patient showing extra oral swelling on the left side of the face

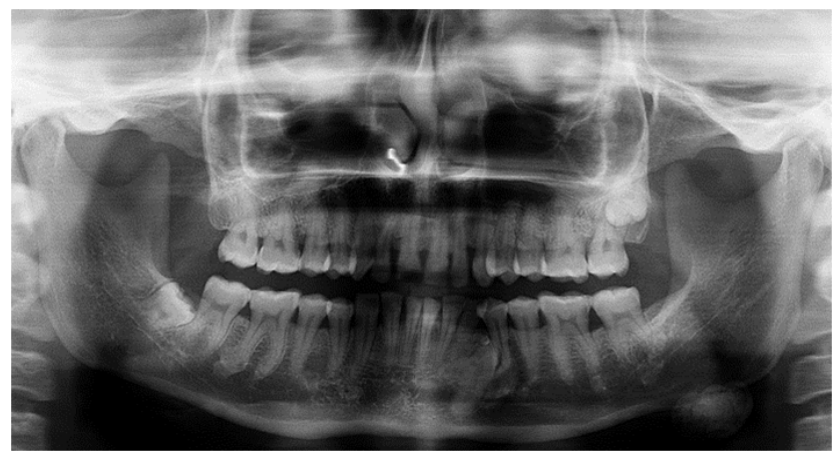

Figure 2: The orthopantamograph reveal a well-defined radiopaque mass in relation to left lower border of mandible.

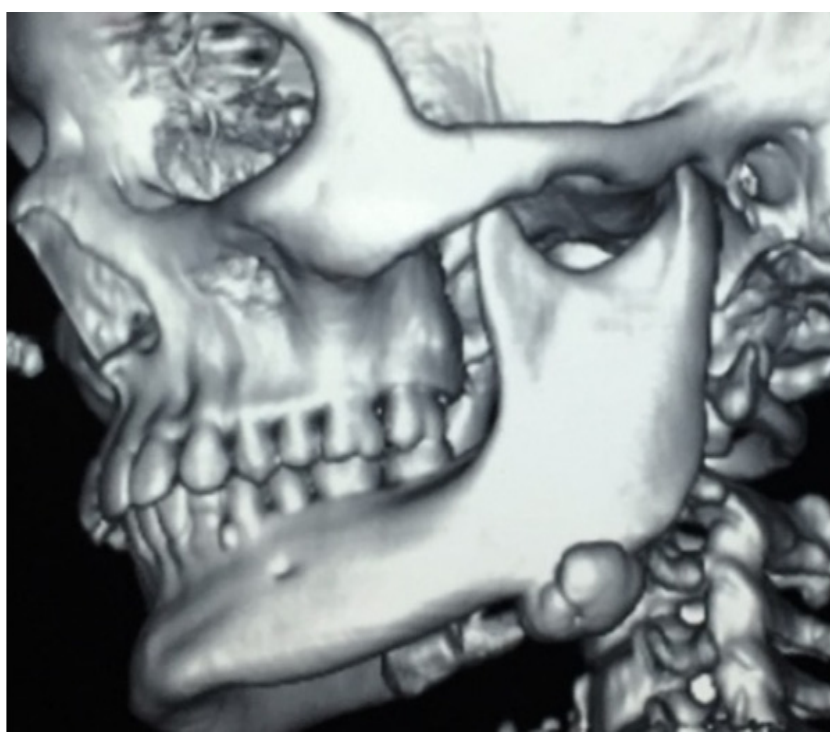

Figure 3: CT with 3D reconstruction view revealed a well-defined radio-dense area attached to the left lower border of mandible

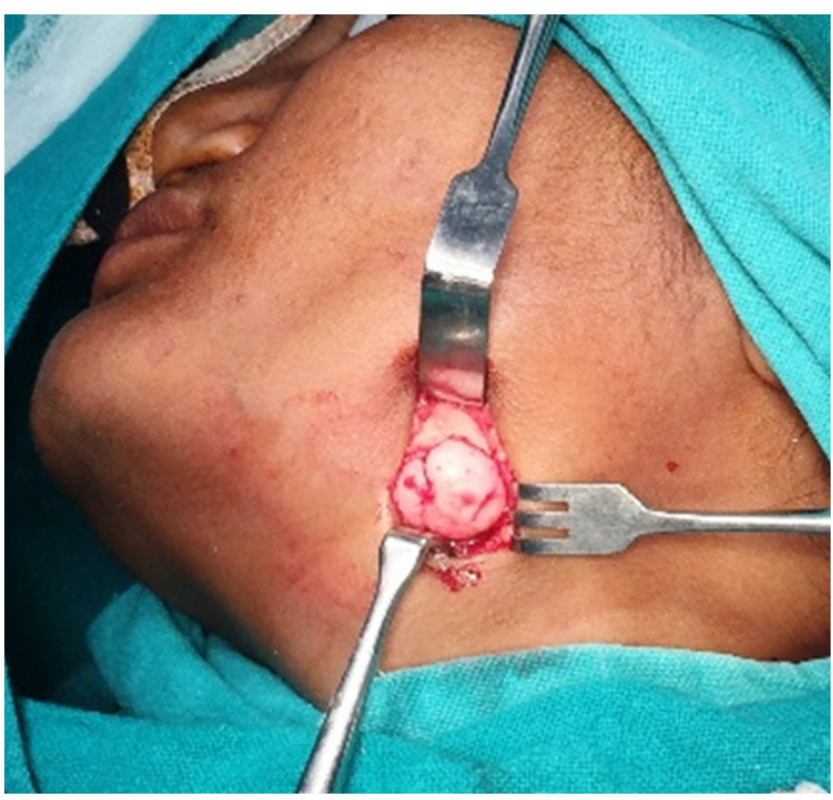

Figure 4: Surgical exposure of the lesion

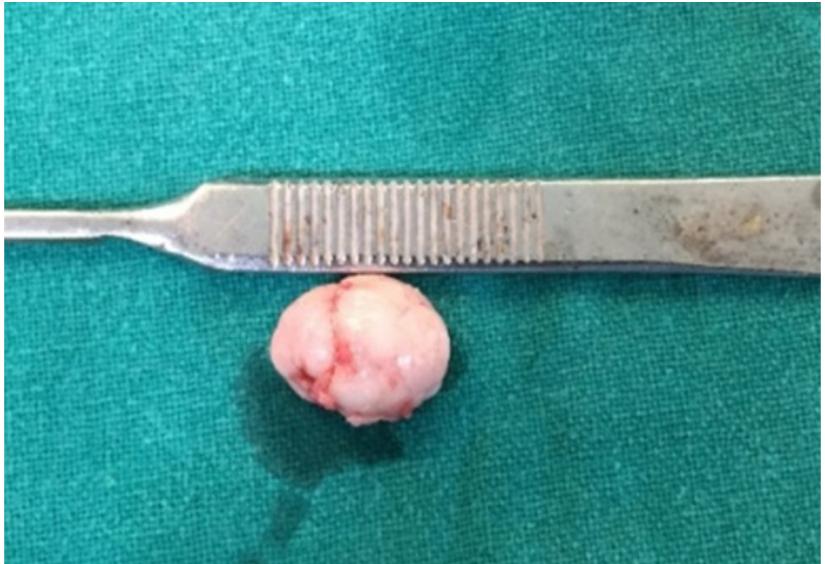

Figure 5: Surgically excised specimen 
Gardner's syndrome should be suspected with the detection of osteoma in the craniofacial region. Patients with this syndrome may present with symptoms of rectal bleeding, diarrhoea, and abdominal pain. The triad of colorectal polyposis, skeletal abnormalities, and multiple impacted or supernumerary teeth is consistent with this syndrome. ${ }^{7}$ In the present case, the lesion was solitary, with no dental or skin anomalies, pain or any intestinal complaints, so it was not considered as Gardner's syndrome. In terms of differential diagnosis, peripheral osteomas of the jaws should be distinguished from other bony exostoses of jaws like tori. Osteoblastoma and osteoid osteomas may present as lingual or buccal bony expansions and should be distinguished from peripheral osteomas. ${ }^{8}$

A peripheral osteoma can be completely treated by surgical intervention. Surgery consists of removing the lesion at the base where it enters the cortical bone. Recurrence after complete excision is very rare and malignant transformation has not been reported in the literature. ${ }^{5}$ Contrary, clinical recurrence following earlier complete or incomplete surgical removal of the growth was seen in a case with osteoma in almost half of the mandible. ${ }^{8}$ In the present case, the patient was reported with a lesion at the angle of the mandible and hence an extraoral approach was used. Though recurrence is not commonly reported, radiographic follow-up on 6 month schedule is recommended for 2-3 years, with 2 additional annual radiographs thereafter.

\section{CONCLUSION}

Peripheral osteoma can infrequently develop and reach large dimensions, most frequent in the mandible. Histopathological examination of lesions is required for definitive diagnosis. Surgical removal is necessary when it causes functional impairment or disfigurement.

\section{REFERENCES}

1. I wai T, Izumi T, Baba J, Maegawa J , Mitsudo K, Tohnai I. Peripheral osteoma of the mandibular notch: report of a case. I ran J Rad 2013; 10(2):74-6.

2. Alves N, Oliveira RD, Deana NF, Freitas NM. Peripheral osteoma in the ramus of mandible: Report of case. Int J Odontostomat 2011; 5(3):215-9.

3. Soni S, Bhargava A. Revisiting peripheral osteoma of the mandible with case series and review of literature. Indian J Otolaryngol Head Neck Surg 2014; 66(2):212-8.

4. Khan S, Chatra L, Shenai KP, Kumar SP. Solitary osteoma of body of the mandible. J Orofac Sci 2013; 5(1):58-60.

5. J ohann AC, de FREITAS J B, de Aguiar MC, de Araujo NS, Mesquita RA. Peripheral osteoma of the mandible: case report and review of the literature. J Craniomaxillofac Surg 2005; 33(4):276-81.

6. Kaplan I, Nicolaou Z, Hatuel D, Calderon S. Solitary central osteoma of the jaws: a diagnostic dilemma. Oral Surg Oral Med Oral Pathol Oral Radiol Endod 2008; 106(3):22-9.

7. Sayan NB, U çok C, Karasu HA, Gunhan O. Peripheral osteoma of the oral and maxillofacial region: a study of 35 new cases. J Oral Maxillofac Surg 2002; 60(11):1299-301.

8. Shetty SK, Biddappa L. Recurrence of a giant peripheral osteoma of mandible. J Maxillofac Oral Surg 2015; $14(1): 452-6$.

\section{Gain quick access to our journal online View our journal at www.nacd.in}

